Revue d'histoire de l'Amérique française

7S REVUE D.HISTOIRE DE L'AMÉRIQUE FRANÇAISE

\title{
La conquête, la liberté et l'adaptation franco-américaine au Pays des Illinois, 1778-1787
}

\section{Robert Englebert et Bronwyn Craig}

Volume 73, numéro 1-2, été-automne 2019

L’Ouest franco-américain

URI : https://id.erudit.org/iderudit/1068790ar

DOI : https://doi.org/10.7202/1068790ar

Aller au sommaire du numéro

\section{Éditeur(s)}

Institut d'histoire de l'Amérique française

\section{ISSN}

0035-2357 (imprimé)

1492-1383 (numérique)

Découvrir la revue

\section{Citer cet article}

Englebert, R. \& Craig, B. (2019). La conquête, la liberté et l'adaptation franco-américaine au Pays des Illinois, 1778-1787. Revue d'histoire de l'Amérique française, 73(1-2), 45-69. https://doi.org/10.7202/1068790ar
Résumé de l'article

Dès l'arrivée des premiers négociants de la traite des fourrures et des missionnaires, le Pays des Illinois se définit par une série d'accommodations culturelles et politiques. Quand des soldats virginiens arrivent à Kaskaskia en 1778 , ils sont les porte-paroles du troisième régime impérial dans la région à prendre place en quinze ans. Les Créoles français cherchent à affirmer leur autonomie politique et culturelle sous cette nouvelle occupation américaine, tout comme ils l'avaient fait sous les régimes français et britannique. Cet article examine les efforts et les tactiques des Créoles français pour résister à l'hégémonie américaine émergente au Pays des Illinois pendant et après la Révolution américaine. Une comparaison des revendications et des actes de résistance à Kaskaskia et à Cahokia démontre que les Créoles de la région vont réussir à faire valoir leurs droits, tout en créant les fondements d'une nouvelle identité franco-américaine.
Tous droits réservés @ Institut d’histoire de l’Amérique française, 2020
Ce document est protégé par la loi sur le droit d'auteur. L’utilisation des services d'Érudit (y compris la reproduction) est assujettie à sa politique d'utilisation que vous pouvez consulter en ligne.

https://apropos.erudit.org/fr/usagers/politique-dutilisation/ 


\title{
La conquête, la liberté et l'adaptation franco-américaine au Pays des Illinois, $1778-1787^{1}$
}

\author{
ROBERT ENGLEBERT \\ Université de la Saskatchewan \\ BRONWYN CRAIG \\ Historienne publique
}

RÉSumÉ • Dès l'arrivée des premiers négociants de la traite des fourrures et des missionnaires, le Pays des Illinois se définit par une série d'accommodations culturelles et politiques. Quand des soldats virginiens arrivent à Kaskaskia en 1778, ils sont les porte-paroles du troisième régime impérial dans la région à prendre place en quinze ans. Les Créoles français cherchent à affirmer leur autonomie politique et culturelle sous cette nouvelle occupation américaine, tout comme ils l'avaient fait sous les régimes français et britannique. Cet article examine les efforts et les tactiques des Créoles français pour résister à l'hégémonie américaine émergente au Pays des Illinois pendant et après la Révolution américaine. Une comparaison des revendications et des actes de résistance à Kaskaskia et à Cahokia démontre que les Créoles de la région vont réussir à faire valoir leurs droits, tout en créant les fondements d'une nouvelle identité franco-américaine.

ABSTRACT - From the arrival of the first French fur traders and missionaries, the Illinois Country was defined by a series of cultural and political accommodations. When Virginian soldiers arrived at Kaskaskia in 1778, it marked a third imperial regime in the region in fifteen years. Much like they had done under the previous French and British regimes, French Creoles sought to assert political and cultural autonomy under American rule. This article considers the challenges that French Creoles faced in resisting emerging American hegemony in Illinois Country, and the strategies that they employed to adapt to new geopolitical cir-

1. Nos remerciements à Guillaume Teasdale, Joseph Gagné, Nicole St-Onge, Jean-François Lozier et aux évaluateurs de la RHAF pour leurs commentaires et leur aide. Toutes les citations de sources en anglais sont traduites librement par l'auteur principal. 
cumstances during and after the American Revolution. A comparison of Creole claims and acts of resistance at Kaskaskia and Cahokia, and their surroundings, shows that they successfully asserted their rights and also set the foundation for a new Franco-American identity.

\section{INTRODUCTION}

Le 4 juillet 1778, George Rogers Clark et 175 soldats de son régiment virginien arrivèrent à Kaskaskia, marquant ainsi le début de l'invasion du Pays des Illinois - un vaste territoire constitué des vallées des rivières Ohio, Wabash, Illinois et de celle du centre du Mississippi. La région offrait un emplacement stratégique pour assurer la défense des villages américains du Kentucky, pour lancer des attaques contre les nations autochtones du Nord-Ouest et pour préparer une expédition contre Détroit, bastion britannique du Pays d'en Haut. Selon Clark, le soutien et la loyauté des Créoles français - un mélange de Canadiens, Français et Louisianais francophones - étaient essentiels au succès de la Révolution américaine à l'ouest des Appalaches'.

Au cours de la décennie suivante, les Créoles cherchèrent à riposter à la conquête virginienne. Ils appuyèrent d'abord les Américains, approvisionnèrent et hébergèrent leurs soldats. Parallèlement, ils développèrent des stratégies pour contester la politique américaine, pour limiter les abus militaires et pour influencer la gouvernance au Pays des Illinois. En l'absence d'un gouvernement civil, un climat d'incertitude politique régna dans les villages créoles jusqu'à l'instauration du Territoire du Nord-Ouest en 1787 et, plus précisément, à l'arrivée du gouverneur Arthur St. Clair en 1790. Cet article examine ainsi l'adaptation des Créoles, principalement ceux des villages de Kaskaskia et de Cahokia et des alentours, au régime américain pendant sa période fondatrice (1778-1787). De plus, il se penche sur la résistance des Créoles face à l'hégémonie américaine dans cette zone limitrophe des empires.

L'histoire des zones limitrophes est étudiée depuis le début du $\mathrm{XX}^{\mathrm{e}}$ siècle. Le concept de borderlands se distingue du modèle nationaliste américain de la frontière expansionniste, dominante et hégémonique en mettant l'accent sur les frontières perméables, les négociations entre peuples, les identités

2. Daniel Royot, Divided Loyalties in a Doomed Empire: The French in the West from New France to the Lewis and Clark Expedition (Newark, University of Delaware Press, 2007), p. 92-94. 


\section{Les villages du Pays des Illinois}

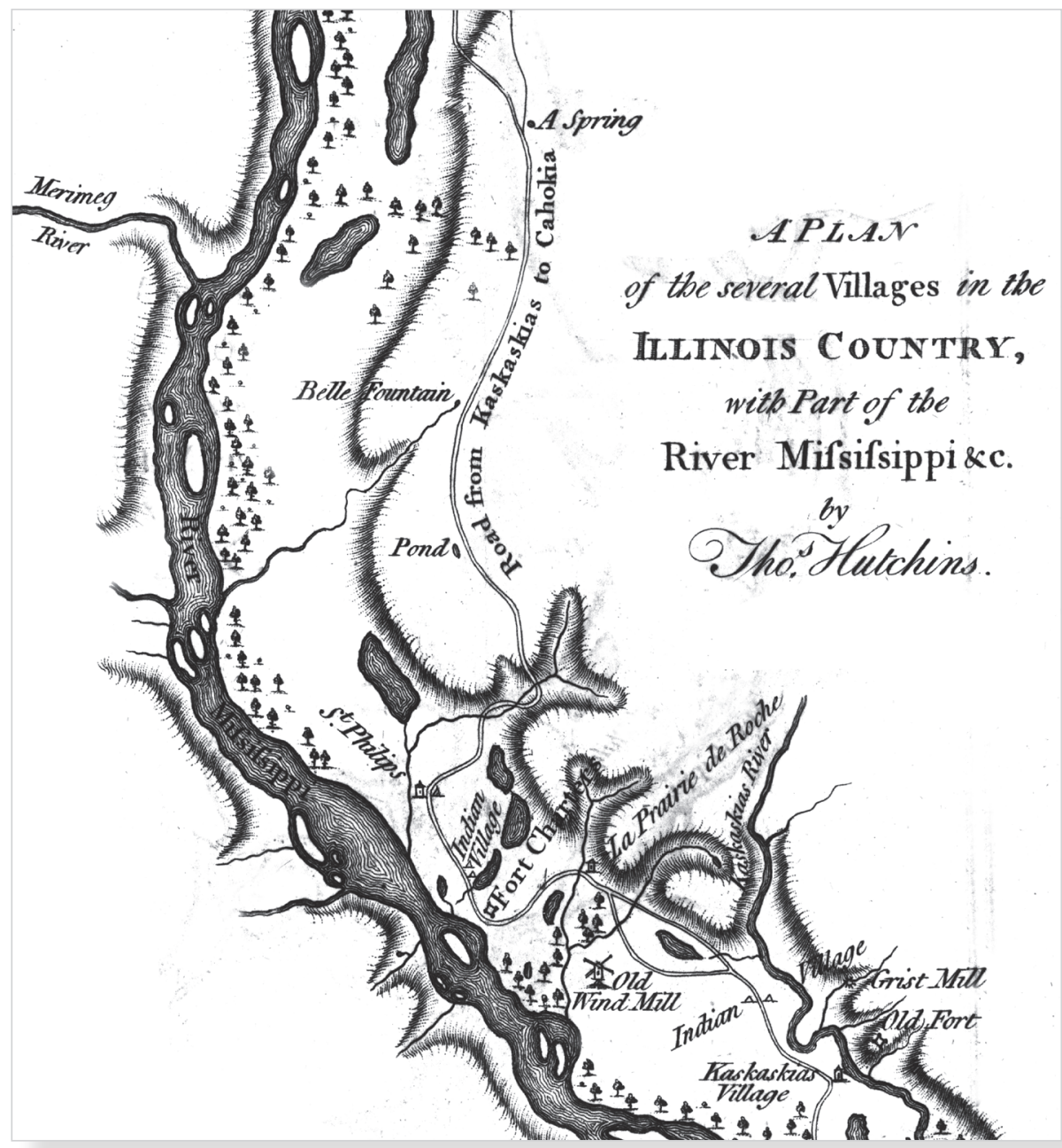

A plan of the several Villages in the Illinois Country, with Part of the River Mississippi \&c. (Londres, Thos. Hutchins, 1778). 
ethniques et la résistance contre l'hégémonie impériale/nationale ${ }^{3}$. Ces dernières années, les spécialistes de l'early America se sont intéressés aux zones limitrophes de la Révolution américaine. Les ouvrages de Colin Calloway, Claudio Saunt, Kathleen DuVal, Alan Taylor et Michael McDonnell nous amènent à l'extérieur des Treize Colonies et révèlent des histoires riches et nuancées ${ }^{4}$. Ils nous forcent à repenser l'importance des peuples qui, à première vue, habitaient aux marges de la Révolution, mais qui occupaient une place stratégique dans ce conflit. Ces populations ressentaient néanmoins les forces hégémoniques d’un empire américain en émergence.

Il est surprenant de constater le peu d'attention qui est accordée à la population créole française au Pays des Illinois par les spécialistes de la Révolution américaine. L'historiographie se fixe en grande partie sur les Américains comme George Rogers Clark, ainsi que sur les victoires et les défaites militaires 5 . Cette piste historiographique anglo-centriste et chauvine marginalise les autres, c'est-à-dire les Autochtones et les francophones, en donnant du poids au mythe fondateur et nationaliste des États-Unis. Quelques-unes des rares enquêtes qui se penchent sur les Créoles dépeignent la disparition supposée de la population francophone au Pays des Illinois. Par exemple, l'étude de Clarence Alvord, au début du XX $\mathrm{XX}^{\mathrm{e}}$ siècle,

3. Frederick Jackson Turner, The Frontier in American History (New York, Henry Holt and Co., 1920); Herbert Eugene Bolton, The Spanish Borderlands: A Chronicle of Old Florida and the Southwest (New Haven, Yale University Press, 1921); David J. Weber, "Turner, the Boltonians, and the Borderlands ", American Historical Review, 91, 1 (1986), p. 66-81; Albert L. Hurtado, «Parkmanizing the Spanish Borderlands: Bolton, Turner, and the Historian's World», Western Historical Quarterly, 26, 2 (1995), p. 149-167; Jeremy Adelman et Stephen Aron, «Borderlands to Borders: Empires, Nation-States, and the Peoples in between in North American History", American Historical Review, 104, 3 (1999), p. 814-841; Evan Haefeli, "A Note on the Use of North American Borderlands", American Historical Review, 104, 4 (1999), p. 1222-1225; Allan Greer, «National, Transnational, and Hypernational Historiographies: New France Meets Early American History ", Canadian Historical Review, 91, 4 (2010), p. 695-724; Pekka Hämäläinen et Samuel Truett, "On Borderlands», Journal of American History, 98, 2 (2011), p. 338-361; voir aussi le numéro thématique «Emerging Borderlands", Michigan Historical Review, 34, 1 (2008).

4. Colin G. Calloway, The American Revolution in Indian Country: Crisis and Diversity in Native American Communities (Cambridge, Cambridge University Press, 1995); Colin G. Calloway, The Shawnees and the War for America (New York, Viking, 2007); Claudio Saunt, West of the Revolution: An Uncommon History of 1776 (New York, W. W. Norton \& Company, 2014); Kathleen DuVal, Independence Lost: Lives on the Edge of the American Revolution (New York, Random House Publishing Group, 2015); Michael McDonnell, Masters of Empire: Great Lakes Indians and the Making of America (New York, Hill and Wang, 2015); Alan Taylor, American Revolutions: A Continental History, 1750-1804 (New York, W. W. Norton \& Company, 2016).

5. Lowell H. Harrison, George Rogers Clark and the War in the West (Louisville, University of Press of Kentucky, 1976); Lois A. Carrier, Illinois: Crossroads of a Continent (Urbana \& Chicago, University of Illinois Press, 1993), p. 25-31; Gregory H. Nobles, American Frontiers: Cultural Encounters and the Continental Conquest (New York, Hill and Wang, 1997), p. 90-91; William R. Nester, George Rogers Clark: "I Glory in War» (Norman, University of Oklahoma Press, 2012); pour une perspective plus nuancée voir James E. Davis, Frontier Illinois (Bloomington \& Indianapolis, Indiana University Press, 1998), p. 67-111. 
souligne qu'une vague d'immigration américaine, dont la révolution marque le début, met fin aux communautés créoles ${ }^{6}$. Un peu plus nuancé, Carl Ekberg déduit que la domination éventuelle des États-Unis se confirma avec le contrôle américain de la farine créole destinée à La Nouvelle-Orléans pendant les années 1770 et $1780^{7}$.

Pourtant, les historiens ne s'attardent pas exclusivement à la disparition ou au déclin créole sous le Régime américain. Margaret Kimball Brown examine la continuité culturelle créole à Prairie du Rocher et, plus récemment, Soazig Villerbu nous rappelle la centralité de l'Église catholique à Vincennes comme instrument de résistance ${ }^{8}$. De plus, Donald Chaput démontre que les Frontier French réagissaient à la Révolution selon leurs propres intérêts, ce qui entraîna des allégeances incertaines ${ }^{9}$.

De manière plus générale, quelques spécialistes dans le champ d'étude élargi de l'histoire franco-américaine du Midwest ont examiné les réactions créoles à l'expansion territoriale américaine après la Révolution. Par exemple, Jay Gitlin soutient que les Créoles participèrent à l'expansion américaine et jouèrent un rôle déterminant dans la création du Midwest américain, en particulier à Saint-Louis au début du XIX ${ }^{\mathrm{e}}$ siècle ${ }^{10}$. L'étude récente de Guillaume Teasdale traite moins de la collaboration politique avec les Américains et examine plutôt les stratégies créoles pour affirmer la continuité du régime foncier dans la zone limitrophe de Détroit à la fin XVIII $^{\mathrm{e}}$ siècle $^{11}$. Lucy Murphy et Catherine Cangany soulignent, par contre, les limites de la résistance créole aux Américains à Prairie du Chien et à Détroit au XIX ${ }^{\mathrm{e}}$ siècle $^{12}$. Ces analyses évoquent toutes, en dépit de leurs différences, une certaine continuité culturelle créole face à la perturbation géopolitique anglo-américaine.

6. Clarence Walworth Alvord, The Illinois Country, 1763-1818 (Springfield, Illinois Centennial Commission, 1920).

7. Carl J. Ekberg, French Roots in the Illinois Country: The Mississippi Frontier in Colonial Times (Urbana et Chicago, University of Illinois Press, 1998), p. 226.

8. Margaret Kimball Brown, History as They Lived It : A Social History of Prairie Du Rocher, Ill. (Tucson, The Patrice Press, 2005); Tangi Villerbu, «Pouvoir, religion et société en des temps indécis: Vincennes, 1763-1795 », Revue d'histoire de l'Amérique française, 62, 2 (2008), p. 185-214.

9. Donald Chaput, "Treason or Loyalty? Frontier French in the American Revolution ", Journal of the Illinois State Historical Society, 71, 4 (1978), p. 242-251.

10. Jay Gitlin, The Bourgeois Frontier: French Towns, French Traders and American Expansion (New Haven, Yale University Press, 2010).

11. Guillaume Teasdale, Fruits of Perseverance: The French Presence in the Detroit River Region, 1701-1815 (Montréal et Kingston, McGill-Queen’s University Press, 2019), p. 82-96.

12. Lucy Eldersveld Murphy, Great Lakes Creoles : a French-Indian Community on the Northern Borderlands, Prairie du Chien, 1750-1860 (New York, Cambridge University Press, 2014); Catherine Cangany, Frontier Seaport: Detroit's Transformation into an Atlantic Entrepôt (Chicago, University of Chicago Press, 2014). 
Revenir sur la persistance créole remet en cause la notion d'une conquête catégorique, caractérisée par la prépondérance d'un empire of liberty américain $^{13}$. Les Virginiens ont conquis le Pays des Illinois militairement, mais ce qui s'est passé par la suite reflète des conjonctures complexes et nuancées. Influencés par les événements au Canada après la Conquête - la proclamation royale et l'Acte de Québec - et conscients de l'occupation américaine de Montréal en $1775^{14}$, les Créoles au Pays des Illinois réagissaient au nouveau régime américain par une combinaison de complicité, de revendications et de continuité culturelle. Les revendications créoles révèlent un potentiel d'adaptation étonnant basé sur l'usage du concept de gouvernement représentatif, de rhétorique républicaine, de droit français et d'une autorité ecclésiastique catholique. En fait, c'est dans cette flexibilité d'approche envers le régime américain qu'on voit les stratégies de la survivance constituant les racines d'une identité franco-américaine.

\section{LE PAYS DES ILLINOIS AVANT LA RÉVOLUTION AMÉRICAINE}

La colonisation franco-catholique s'étendit dans le Pays des Illinois aux $\mathrm{XVII}^{\mathrm{e}}$ et $\mathrm{XVIII}^{\mathrm{e}}$ siècles par l'entremise de relations complexes avec les nations autochtones ${ }^{15}$. Cette zone limitrophe impériale au sein de territoires autochtones se trouvait sujette aux prétentions du gouverneur de Québec jusqu'en 1717. Elle fut alors rattachée à la colonie de la Louisiane jusqu'à la fin de la guerre de Sept Ans ${ }^{16}$. La population coloniale qui se développa au Pays des Illinois est difficile à catégoriser, car les migrants

13. Erik Hinderaker, Elusive Empires : Constructing Colonialism in the Ohio Valley, 1673-1800 (Cambridge, Cambridge University Press, 1997), p. 269-270.

14. Voir aussi Patrick Lacroix, «Promises to Keep: French Canadians as Revolutionaries and Refugees, 1775-1800 ", Journal of Early American History, 9, 1 (2009), p. 59-82.

15. Margaret Kimball Brown, «La colonisation française de l'Illinois: une réévaluation», Revue d'histoire de l'Amérique française, 39, 4 (1986), p. 583-591; Cécile Vidal, «Le Pays des Illinois, six villages français au cœur de l'Amérique du Nord, 1699-1765", dans Thomas Wien, Cécile Vidal et Yves Frenette, dir., De Québec à l'Amérique française, histoire et mémoire: textes choisis du deuxième colloque de la Commission franco-québécoise sur les lieux de mémoire communs (Québec, Les Presses de l’Université Laval, 2006), p. 125138; Tracy Neal Leavelle, The Catholic Calumet: Colonial Conversions in French and Indian North America (Philadelphie, University of Pennsylvania Press, 2011); Robert Michael Morrissey, "The Terms of Encounters: Language and Contested Visions of French Colonization in the Illinois Country, 1673-1702", dans Robert Englebert et Guillaume Teasdale, dir., French and Indians in the Heart of North America, 16301815 (East Lansing, Michigan State University Press, 2013), p. 43-75; Sophie White, Wild Frenchmen and Frenchified Indians: Material Culture and Race in Colonial Louisiana (Philadelphie, University of Pennsylvania Press, 2013).

16. Paul A. Demers, «The French Colonial Legacy of the Canada-United States Border in Eastern North America, 1650-1783", French Colonial History, 10 (2009), p. 35-54; pour les changements de juridiction coloniale Canada/Louisiane, voir aussi Khalil Saadani, «Le Gouvernement de la Louisiane Française, 1731-43: essai d'histoire comparative», French Colonial History, 4 (2003), p. 117-132. 
du Canada, de la France et de la Louisiane, ainsi que l'esclavage de Noirs et d'Autochtones, sans compter le phénomène de métissage, produisent une société complexe et hétérogène ${ }^{17}$. Bien que les mots «Français» et «Francophones» aient été employés régulièrement dans les études historiques, «Créole» s'est répandu en vue d'identifier les colons francophones libres qui se sont installés dans la région ${ }^{18}$.

L'historiographie dévoile plusieurs interprétations distinctes au sujet de cette société créole. Certains historiens mettent l'accent sur l'esprit d'indépendance réputé des Créoles, argument semblable au concept de «la colonisation délinquante» évoqué par Shannon Lee Dawdy dans son analyse de La Nouvelle-Orléans ${ }^{19}$. Comprise comme une grande étendue géographique en dehors du contrôle impérial, cette piste historiographique dépeint le Pays des Illinois comme isolé, grouillant de coureurs de bois et d'autres individus cherchant une liberté associée à la frontière ${ }^{20}$. D’autres chercheurs, notamment Carl Ekberg, présentent la société créole au Pays des Illinois comme étant beaucoup plus ancrée. Selon leur interprétation, les colons partageaient la même mentalité française que leurs compatriotes en métropole et par conséquent reproduisirent les mêmes structures villageoises ${ }^{21}$. La tension entre la liberté créole et le patrimoine culturel français devint la caractéristique coloniale fondamentale du Pays des Illinois. Elle est essentielle pour comprendre l'adaptation créole au Régime américain.

17. Cécile Vidal, «Les implantations françaises au Pays des Illinois au XVIII siècle, 1699-1765 », thèse de doctorat (histoire), École des Hautes Études en Science Sociales (EHESS) et Centre d'Études NordAméricaines (CENA), 1995.

18. J. Gitlin, The Bourgeois Frontier..., p. 191; L. E. Murphy, Great Lakes Creoles..., p. 10-18; Tangi Villerbu, «Introduction», dans Guillaume Teasdale et Tangi Villerbu, dir., Une Amérique Française, 17601860 : Dynamique du Corridor Créole (Paris: Les Indes savantes, 2015), p. 10-14.

19. Shannon Lee Dawdy, Building the Devil's Empire: French Colonial New Orleans (Chicago et Londres, University of Chicago Press, 2008), p. 18-21; pour un argument plus nuancé, voir Cécile Vidal, «De province à colonie et de Français à Louisianais, le langage de la nation et la construction coloniale de l'empire à La Nouvelle-Orléans en 1768-1769", dans Cécile Vidal, dir., Français? La Nation en débat entre colonies et métropole, XVI ${ }^{e}$-XIX ${ }^{e}$ siècle (Paris, Éditions de l'École des Hautes Études en Sciences Sociales, 2014), p. 98; Nathalie Dessens et Jean-Pierre Le Glaunec, dir., Interculturalité : la Louisiane au carrefour des cultures (Québec, Les Presses de l’Université Laval, 2016).

20. Winstanley Briggs, «Le Pays des Illinois», The William and Mary Quarterly, 47, 1 (1990), p. 55 ; Gilbert C. Din, "Empires Too Far: The Demographic Limitations of Three Imperial Powers in the Eighteenth-Century Mississippi Valley", Louisiana History: The Journal of the Louisiana Historical Association, 50, 3 (2009), p. 271; Daniel Royot, Divided Loyalties in a Doomed Empire, p. 26, 100. Pour l'étude la plus complète sur les coureurs de bois, voir: Gilles Havard, Histoire des coureurs de bois: Amérique du Nord, 1600-1840 (Paris, Les Indes savantes, 2016).

21. C. J. Ekberg, French Roots..., p. 46-54; Natalia Maree Belting, Kaskaskia under the French Regime (Carbondale, University of Southern Illinois Press, 2003). 
L'occupation virginienne entraîna un troisième régime impérial en quinze ans au Pays des Illinois - français, britannique, américain. Pour les Créoles, l'arrivée des Américains représentait non seulement une conquête, mais aussi l'occasion d'influencer le gouvernement, d'exprimer une autonomie locale et de résister à l'hégémonie américaine émergente. L'historien Robert Michael Morrissey affirme que les Créoles jouissaient d'une autonomie locale pendant la première moitié du XVIII ${ }^{e}$ siècle par l'entremise de la collaboration entre les Autochtones Illinois et les officiers coloniaux français ${ }^{22}$. À partir de cette culture de collaboration, les Créoles cherchèrent à établir des liens avec les autorités britanniques après le traité de Paris de $1763^{23}$. Plus spécifiquement, ils invoquèrent la tradition britannique du gouvernement représentatif pour revendiquer une autonomie locale. Par exemple, pendant l'été 1770, le marchand Daniel Blouin revendiqua au nom des habitants de Kaskaskia la création d'un gouvernement civil, s'inspirant de la colonie du Connecticut ${ }^{24}$. Bien que le général Thomas Gage ait rejeté la proposition, cette demande démontre néanmoins l'esprit collaboratif avec lequel les Créoles abordèrent la question de la gouvernance impériale au Pays des Illinois ${ }^{25}$. L’Acte de Québec de 1774 présenta encore une fois l'occasion d'établir un gouvernement civil. Malheureusement, à cause des troubles dans les Treize Colonies, la Grande-Bretagne retira ses régiments du Pays des Illinois et le projet d'un gouvernement représentatif fut abandonné. En fait, avec un seul administrateur colonial, et sans soldats pour défendre la région, la Grande-Bretagne renonça à ses prétentions impériales au Pays des Illinois au profit des Américains. Néanmoins, la population créole n'oublia pas l'Acte de Québec et les moyens qu'il proposait pour maintenir le droit français et la religion catholique au sein d'un nouveau régime ${ }^{26}$.

\section{LE RÉGIME VIRGINIEN ET LE COMTÉ DE L'ILLINOIS}

L'absence de violence au début de l'occupation américaine donna l'apparence d'un climat paisible. Il y eut même des fêtes pour souligner l'arrivée des Virginiens ${ }^{27}$. Mais après avoir rencontré les Créoles à Kaskaskia, Clark

22. R. M. Morrissey, Empire by Collaboration..., p. 61.

23. R. M. Morrissey, Empire by Collaboration..., p. 223.

24. Clarence Edwin Carter, Great Britain and the Illinois Country, 1763-1774 (Washington, The American Historical Association, 1910), p. 156.

25. R. M. Morrissey, Empire by Collaboration..., p. 3-5.

26. Robert Englebert, «The Legacy of New France: Law and Social Cohesion between Quebec and the Illinois Country, 1763-1790", French Colonial History, 17 (2017), p. 38-42.

27. J. Gitlin, The Bourgeois Frontier..., p. 37. 
perçut chez ces derniers une vive inquiétude, "comme s'ils venaient au tribunal pour déterminer leur destin pour toujours ${ }^{28}$ ». Il les rassura «qu'ils devraient jouir de tous les privilèges de la gouvernance américaine et la garantie de sécurité de toute leur propriétée ${ }^{29}$ ». Les Créoles avaient néanmoins de sérieuses réserves, et toute collaboration avec les nouveaux conquérants était stratégique ${ }^{30}$. Ils feignirent une méconnaissance de la révolution pour gagner du temps et évaluer leurs options ${ }^{31}$. Malgré la tendance à dépeindre le Pays des Illinois comme un endroit isolé, les Créoles étaient bien informés au sujet des événements qui se déroulaient dans les colonies lointaines $^{32}$. Ils profitaient des anciens réseaux de commerce du corridor créole qui s'étendait de Québec à La Nouvelle-Orléans et se tenaient aussi au courant de la guerre grâce à la correspondance avec quelques contacts à Philadelphie ${ }^{33}$.

Pendant l'année 1778, plusieurs Créoles devinrent des ambassadeurs de bonne foi pour faciliter leur transition de sujets britanniques à citoyens américains. Les membres de la milice de Kaskaskia acceptèrent d'accompagner l'expédition du commandant Bowman au village de Cahokia dont l'objectif, selon Clark, était d'encourager «le peuple à se soumettre à un destin plus agréable ${ }^{34}$ ». Le plan fut un succès. En rencontrant leurs voisins, associés et parents venant de Kaskaskia, les Créoles de Cahokia capitulèrent devant les Américains. L'expédition continua vers le nord. Le 13 juillet 1778, un médecin de Kaskaskia, Jean-Baptiste Laffont, et l'abbé Pierre Gibault, sympathisant avec le nouveau régime, lurent à haute voix un discours de Clark invitant les habitants de Vincennes à accepter la citoyenneté américaine. Une semaine plus tard, les Créoles prêtèrent serment d’allégeance aux États-Unis ${ }^{35}$.

28. George Rogers Clark to George Mason, 19 novembre 1779, dans James Alton James, dir., The George Rogers Clark Papers, 1771-1781 (Springfield, Trustees of the Illinois State Historical Library), p. 120.

29. George Rogers Clark to George Mason, 19 novembre $1779 \ldots$, p. 121.

30. D. Chaput, "Treason or Loyalty?...", p. 251 ; Lawrence B. A. Hatter, Citizens of Convenience: The Imperial Origins of American Nationhood on the U.S.-Canadian Border (Charlottesville, University of Virginia Press, 2017), p. 10-12.

31. Clarence Walworth Alvord, dir., Cahokia Records 1778-1790 (Springfield, Trustees of the Illinois State Historical Library, 1907), p. xxxvi.

32. Robert Englebert, «Merchant Representatives and the French River World, 1763-1803», Michigan Historical Review, 34, 1 (2008), p. 63-82.

33. J. Gitlin, The Bourgeois Frontier..., p. 27-28; Chester County Courthouse, Chester Illinois, Kaskaskia Manuscripts (KM), lettre de Henry Hamilton, $77: 12:--: 1$.

34. George Rogers Clark to George Mason, 9 novembre 1779, dans J. A. James, dir., The George Rogers Clark Papers, 1771-1781, p. 122.

35. Clark to the Inhabitants of Vincennes, [13 ?] juillet 1778; Clark to Jean B. Laffont, 14 juillet 1778; Oath of Inhabitants of Vincennes, 20 juillet 1778, dans J. A. James, dir., The George Rogers Clark Papers, 1771-1781, p. 50-59. 
L'apparence d'une transition pacifique vers le régime américain masquait une réalité plus dramatique. Laffont et Gibault comprenaient bien qu'ils étaient obligés de collaborer avec les Virginiens, autrement ils risquaient de se faire attaquer ${ }^{36}$. Le lendemain de son arrivée à Kaskaskia, Clark posta des soldats à la résidence de l'influent marchand Gabriel Cerré. La raison était claire: cette démonstration de force devait convaincre les marchands du village d'approvisionner le régiment virginien ${ }^{37}$.

Le 9 décembre 1778, l'assemblée générale de la Virginie fonda le comté d'Illinois, le gouvernement provisoire devant ouvrer pendant trois ans $\mathrm{s}^{38}$. En réalité, il s'agissait d'un régime militaire presque identique à celui de l'administration coloniale précédente, ce qui témoignait du fait que les Treize Colonies étaient toujours en guerre contre la Grande-Bretagne. Les attaques des Chaouanons (ou Shawnees) contre les villages dans le Kentucky et la capture de Daniel Boone en 1778 démontraient la fragilité du régime américain et faisaient craindre que les forces britanniques et autochtones pourraient encercler et reprendre le Pays des Illinois. La priorité virginienne était de garder le contrôle du Pays des Illinois et de préparer une expédition pour prendre Détroit aux Britanniques.

Le gouverneur de la Virginie fit confiance à ses nouveaux citoyens francophones, remarquant que les Créoles accorderaient leur soutien sans condition pour assurer la victoire américaine ${ }^{39}$. Il prenait peut-être ses désirs pour la réalité parce que les habitants du Pays des Illinois avaient d'autres idées. Ils utilisèrent des pétitions pour contester l'autorité militaire et influencer la gouvernance américaine. À peine un mois après la création du comté d'Illinois, les Créoles présentèrent à George Rogers Clark une pétition qui accusait les soldats virginiens d'avoir perturbé la tranquillité du village. Plus spécifiquement, ils alléguaient que ces soldats avaient incité du brigandage, en troquant des biens et de l'alcool avec les esclaves, en pleine contradiction des lois du pays. Clark réagit à la pétition avec une ordonnance interdisant la vente de boissons et le rassemblement des esclaves ${ }^{40}$. Malgré

36. T. Villerbu, «Pouvoir, religion et société...», p. 200.

37. Clark to Bowman, 1791 [?], dans J. A. James, dir., The George Rogers Clark Papers, 1771-1781, p. 228229, 235 ; Gabriel Cerré to George R. Clark, 11 juillet 1778, dans Clarence Walworth Alvord, dir., Kaskaskia Records (Springfield, Trustees of the Illinois State Historical Library, 1909), p. 48-49.

38. KM, traduction de l'ordre de l'assemblée générale de la Virginie établissant le comté d’Illinois, $78: 12: 15: 1$.

39. Instructions from Governor Patrick Henry to John Todd, 12 décembre 1778, dans J. A. James, dir., The George Rogers Clark Papers, 1771-1781, p. 84.

40. Proclamation by George Rogers Clark, 24 décembre 1778, dans C. Walworth Alvord, dir., Kaskaskia Records..., p. 65 ; M. Scott Heerman, The Alchemy of Slavery: Human Bondage and Emancipation in the Illinois Country, 1730-1865 (Philadelphie, University of Pennsylvania Press, 2018); Cécile Vidal, 
les mesures cherchant à limiter les abus des soldats, cet épisode illustre le fossé culturel et la croissance des tensions entre les Créoles et les Virginiens. Le fait que les habitants approvisionnaient et hébergeaient déjà les Américains contribua à aggraver la situation. En date du 31 août 1779, les Créoles à Kaskaskia avaient fourni 54600 livres de farine aux Américains ${ }^{41}$, une "nécessité du service ${ }^{42}$ », selon Clark. Les Américains payèrent la farine, mais les billets des États-Unis se déprécièrent au cours de la Révolution.

L'établissement des cours de justice et les élections de magistrats au Pays des Illinois en mai 1779 ne réussirent pas à apaiser les Créoles ${ }^{43}$. Au contraire, ces derniers utilisèrent la nouvelle institution pour se plaindre des abus des Américains. Le 21 mai, neuf jours après la cérémonie faisant de John Todd, un Virginien qui habitait au Kentucky, le lieutenant du comté, les magistrats créoles de la cour de Kaskaskia lui présentèrent une pétition contre les soldats virginiens ${ }^{44}$. Ils déclarèrent que les soldats volaient des animaux d'élevage, vendaient de l'alcool aux Autochtones et persistaient à entretenir un commerce illicite avec les esclaves. Selon les magistrats, ces abus étaient «... contre toutes Loix et Particulierement contre les Coutumes et uzages d'un pais libre et independenant comme est celui $\mathrm{cy}^{45}$ ». Dans le contexte de changement de régime, les Canadiens de l'axe laurentien et les Louisianais de la Basse Louisiane utilisèrent aussi ce genre de pétition comme moyen de protestation ${ }^{46}$.

Les magistrats préparèrent une version préliminaire d'une ordonnance du tribunal qui imposait des restrictions pour empêcher la mauvaise conduite des soldats ${ }^{47}$. Le lieutenant Todd n'acceptera cependant pas de

"Africains et Européens au pays des Illinois durant la période française (1699-1765)», French Colonial History, 3 (2003), p. 51-68; Winstanley Briggs, «Slavery in French Colonial Illinois », Chicago History, 18 (1989-1990), p. 66-81.

41. List of contributors made by Patrick Kennedy, Assistant Commissary, 31 août 1779, dans C. Walworth Alvord, dir., Kaskaskia Records..., p. 116.

42. Proclamation Prohibiting Exports by Gabriel Cerré, 28 juin 1779; Certificate from George Rogers Clark, 14 juillet 1779, dans C. Walworth Alvord, dir., Kaskaskia Records..., p. 101, 105.

43. Speech of George R. Clark to the Inhabitants of Kaskaskia, 12 mai 1779; Certificate of Election by John Todd, 21 mai 1779, dans C. Walworth Alvord, dir., Kaskaskia Records..., p. 80-81, 86; KM, Election of Jean-Baptiste Barbau as first judge and Antoine Duchaufour de Louvières as second judge of Prairie du Rocher, $1779: 05: 19: 1$.

44. Magistrates to John Todd, 21 mai 1779, dans C. Walworth Alvord, dir., Kaskaskia Records..., p. 88-93.

45. Magistrates to John Todd, 21 mai 1779, dans C. Walworth Alvord, dir., Kaskaskia Records..., p. 93.

46. Hannah Weiss Muller, «From Requête to Petition: Petitioning the Monarch between Empires», The Historical Journal, 60, 3 (2017), p. 659-86; C. Cangany, Frontier Seaport..., p. 117; S. L. Dawdy, Building the Devil's Empire..., p. 221.

47. Proclamation Prohibiting Exports by Gabriel Cerré, 28 juin 1779, dans C. Walworth Alvord, dir., Kaskaskia Records 1778-1790..., p. 101. 
signer l'ordonnance sans l'ajout d'un article restreignant les exportations du Pays des Illinois. Ce qui avait été conçu comme loi pour protéger les habitants au Pays des Illinois devint un embargo sur le commerce intercolonial au détriment des Créoles. Deux mois plus tard, Todd annonça des restrictions encore plus sévères ${ }^{48}$.

La frustration des Créoles était évidente partout au Pays des Illinois, mais en particulier à Kaskaskia, où la majorité des soldats virginiens étaient cantonnés chez les habitants ${ }^{49}$. En décembre 1779 , les mécontents signèrent une pétition adressée aux magistrats leur demandant: «Est-il bientôt temps Que vous metiés ordre aux brigandages Et a la tyrannnie que le militaire Exerce sur nous tous les Jours ${ }^{50}$ ?» Dans une certaine mesure, les plaintes des Créoles n'étaient pas bien différentes de celles de la population à Valley Forge et aux alentours, en Pennsylvanie, où les soldats saisirent les biens nécessaires pour approvisionner l'armée américaine pendant l'hiver 1778$1779^{51}$. Le Pays des Illinois se distinguait toutefois des Treize Colonies, car il n'y eut pas de guerre civile. En plus, il n'y avait pas une grande tradition de droit anglais, ce qui explique pourquoi l'indignation au sujet de la taxation ou de la possible abolition de l'esclavage n'y fut pas aussi marquée que dans ces colonies ${ }^{52}$.

Voyant leur territoire conquis et entraîné dans une guerre civile angloaméricaine, les Créoles du Pays des Illinois saisirent toute occasion de revendiquer leurs droits sous le nouveau régime. L'échec des pétitions basées sur leurs anciens droits coloniaux amena un changement de tactique. Les notables possédaient des bibliothèques contenant des volumes sur la philosophie et la politique et suivaient les grands débats intellectuels du

48. Proclamation, p. 23-24, dans Edward G. Mason, dir., Early Chicago and Illinois (Chicago, Fergus Printing Company, 1890), p. 306.

49. Charles van Ravenswaay, "Affairs at Fort Bowman, 1778-1780 : Accounts and Letters », dans John Francis McDermott, dir., Old Cahokia (St. Louis, The St. Louis Historical Documents Foundation, 1949), p. 222; James Alexander Thom, "George Rogers Clark and the American Indian», dans Kenneth C. Carstens et Nancy Son Carstens, dir., The Life of George Rogers Clark, 1752-1818: Triumphs and Tragedies (Westport, Praeger Publishers, 2004), p. 44.

50. Protest of Inhabitants to the Magistrates, 8 décembre 1779, dans C. Walworth Alvord, dir., Kaskaskia Records..., p. 138-139.

51. E. Wayne Carp, To Starve the Army at Pleasure: Continental Army Administration and American Political Culture 1775-1783 (Chapel Hill, The University of North Carolina, 1984), p. 96-97. Les habitants à Valley Forge et des alentours étaient principalement d'origine anglo-américaine et allemande.

52. Jack P. Greene, The Constitutional Origins of the American Revolution (Cambridge, Cambridge University Press, 2011); Justin du Rivage, Revolution Against Empire: Taxes, Politics, and the Origins of American Independence (New Haven, Yale University Press, 2017); Ira Berlin et Ronald Hoffman, dir., Slavery and Freedom in the Age of the American Revolution (Urbana et Chicago, University of Illinois Press, 1986). 
monde atlantique dans les années précédant la Révolution américaine ${ }^{53}$. Par ailleurs, le conseil exécutif de la Virginie avait donné instruction à Clark de distribuer des copies de la Déclaration d'indépendance et de la Déclaration des droits de la Virginie dès son arrivée au Pays des Illinois ${ }^{54}$. Donc, au moins une portion de la population créole comprenait les principes essentiels de la liberté américaine ${ }^{55}$. Au-delà des principes idéologiques, les Créoles saisirent la révolution comme l'occasion d'exprimer leur autonomie locale en utilisant leur nouvelle citoyenneté américaine de manière stratégique en vue d'influencer la gouvernance virginienne. S’inspirant de la rhétorique républicaine, ils rappelèrent aux magistrats créoles de Kaskaskia, en décembre 1779, que "C’est à vous En qui Nous avons mis notre Confience Et que nous avons Elus pour Gouverner ce pais soutenu des loix que vous nous avés fait annonçer dans votre Greff ${ }^{56}$ ». Répondant à l'appel des habitants de Kaskaskia, les magistrats soumirent leur propre pétition au commandant américain, John Montgomery, en utilisant l'article 13 de la Déclaration des droits de la Virginie pour revendiquer leurs droits comme citoyens américains ${ }^{57}$. La pétition se terminait par la menace de faire appel directement au gouverneur de la Virginie ${ }^{58}$.

Les officiers civils et militaires, comme John Todd, John Montgomery et Richard Winston, insistèrent auprès des Créoles pour qu'ils abandonnent leurs demandes ${ }^{59}$. Malgré les abus des soldats, qui violaient les principes fondamentaux de la révolution, la nécessité d'approvisionner l'armée était plus importante que le mécontentement des nouveaux citoyens. La situation financière causée par la guerre obligea les Virginiens à payer les marchands créoles avec des billets à ordre sans valeur, un problème répandu partout dans la nouvelle république américaine ${ }^{60}$. Il devint évident que les

53. John Francis McDermott, Private Libraries in Creole Saint Louis (Baltimore, Johns Hopkins University Press, 1938); John Neal Hoover, «Private Libraries and Global Worlds: Book and Print Culture in Colonial St. Louis", dans Jay Gitlin, Barbara Berglund et Adam Arenson, dir., Frontier Cities: Encounters at the Crossroads of Empire (Philadelphie, University of Pennsylvania Press, 2013), p. 190-199.

54. Instructions to Clark from the Virginia Council, 12 décembre 12, 1778, dans J. A. James, dir., The George Rogers Clark Papers, 1771-1781, p. 80.

55. Sur le concept de liberté, voir Michel Ducharme, Le concept de liberté au Canada à l'époque des révolutions atlantiques (1776-1838) (Montréal et Kingston, McGill-Queen’s University Press, 2010), p. 5-8.

56. Protest of Inhabitants to Magristrates, 8 décembre 1779, dans C. Walworth Alvord, dir., Kaskaskia Records..., p. 136-137.

57. The Magistrates to John Montgomery, 8 décembre 1779, dans C. Walworth Alvord, dir., Kaskaskia Records..., p. 140-142.

58. The Magistrates to John Montgomery, p. 142.

59. John Montgomery to George R. Clark, 2 octobre 1779, dans C. Walworth Alvord, dir., Kaskaskia Records..., p. 126-127; John Todd to Richard Winston, p. 18, dans Edward G. Mason, dir., Early Chicago and Illinois..., p. 302.

60. E. W. Carp, To Starve the Army at Pleasure..., p. 68, 75-98. 
comptes des marchands créoles ne seraient pas réglés ${ }^{61}$. Par exemple, à Kaskaskia, le marchand Gabriel Cerré se fit payer 1238 piastres, une somme qui ne représentait qu'une fraction de la valeur réelle du montant dû, une valeur équivalant à 1000 peaux de chevreuil n'ayant pas été remboursée $e^{62}$. Le marchand Charles Gratiot rencontra le même problème à Cahokia. Les Américains avaient promis à Gratiot 2880 piastres pour les biens qu'il était allé acheter à Saint-Louis ${ }^{63}$. Payé en monnaie américaine sans valeur par une administration ne tenant pas ses promesses, Gratiot écrivit que la situation était «contre toute attente» et que «la monnaie en papier [américaine]

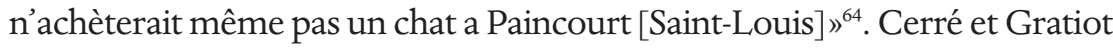
déménagèrent donc à Saint-Louis, sur l'autre rive du Mississippi, en territoire espagnol (haute Louisiane), entre 1780 et 1781. Plusieurs Créoles les suivirent $t^{65}$.

Les Créoles traversaient souvent la frontière fluviale entre les États-Unis et l'empire espagnol afin de maintenir des liens commerciaux, familiaux et culturels. Cependant, ce n'était pas tous les Créoles sur la rive est qui voulaient déménager en territoire espagnol. La vie quotidienne sous le régime américain était difficile bien sûr, avec les abus militaires, les restrictions commerciales et la monnaie sans valeur. Mais face à l'option de renoncer à leurs propriétés, soit par la vente ou par la cession de leurs biens immobiliers, les Créoles cherchaient des alternatives à la migration. Depuis septembre 1778, le bruit courait que la France récupérerait ses anciennes colonies en Amérique septentrionale ${ }^{66}$. Clark avait utilisé l'alliance francoaméricaine pour encourager la loyauté des Créoles et des Autochtones au Pays des Illinois ${ }^{67}$. L'arrivée d'un officier français qui servait Clark et les Virginiens, Augustin Mottin de La Balme, pendant l'été 1780, leur donna l'occasion de renouveler leurs revendications en vue d'obtenir des droits de citoyenneté et l'établissement d'un gouvernement civil.

61. Clark to Patrick Henry, 29 avril 1779, dans J. A. James, dir., The George Rogers Clark Papers, 17711781, p. 173.

62. C. van Ravenswaay, "Affairs at Fort Bowman...", p. 233.

63. Promissary Note of J. Harrod and J. Williams, 9 novembre 1778, dans C. Walworth Alvord, dir., Kaskaskia Records..., p. 59-60; Clerk’s Record, août 1779, dans C. Walworth Alvord, dir., Cahokia Records..., p. 463.

64. Gratiot to John Kay, Cahokia, le 26 avril 1779; Gratiot to McCarty, Cahokia, le 9 novembre 1779; Gratiot to Montgomery, Cahokia, le 15 novembre 1779, dans John Francis McDermott, dir., Old Cahokia, p. 206-207, 226-228.

65. J. Gitlin, Bourgeois Frontier..., p. 36-43.

66. M. Monforton to Gabriel Cerré, 22 septembre 1778; Proclamation by Montgomery, Winston, and St. Germain, 6 mai 1780, dans C. Walworth Alvord, dir., Kaskaskia Records..., p. 54, 156-158.

67. Instructions to Clark from the Virginia Council, 12 décembre 1778, dans J. A. James, dir., The George Rogers Clark Papers, 1771-1781, p. 80. 
Le Balme était sympathique à la cause des Créoles. Après avoir entendu les plaintes des habitants, il suggéra aux Créoles de pétitionner à l'assemblée virginienne et auprès d'Anne-César, marquis de La Luzerne, l'ambassadeur de France aux États-Unis, en leur demandant l'évacuation des soldats américains du Pays des Illinois ${ }^{68}$. Le Français avait des contacts influents, parmi eux Benjamin Franklin et George Washington, et était donc bien placé pour être médiateur. C'est notamment pour cette raison que les habitants de Kaskaskia et de Cahokia lui demandèrent de les représenter ${ }^{69}$. Malheureusement, La Balme fut tué au combat à Kekionga (Fort Wayne, Indiana) en novembre 1780, moins de six mois après son arrivée au Pays des Illinois ${ }^{70}$.

Après la mort de La Balme, le Pays des Illinois atteignit un seuil critique. Une série de chefs militaires indifférents aux revendications créoles et les abus incessants des soldats produisirent une situation insupportable. En mai 1781, les Créoles à Kaskaskia adressèrent une pétition au gouverneur de la Virginie, Thomas Jefferson, mais il ne répondit pas. Le silence de Jefferson est attribuable probablement aux effets de l'invasion britannique de la Virginie et à l'incendie de la capitale, Richmond, en janvier, suivis par la dissolution temporaire de l'assemblée virginienne jusqu'en juin $1781^{71}$. Les Américains répondirent aux attaques britanniques par une campagne militaire concertée dans le sud qui culmina avec la victoire de Yorktown le 19 octobre 1781. Le traité de Paris de 1783 clôt officiellement la guerre, mais ce sont les articles de capitulation à Yorktown qui mirent fin aux combats entre les Américains et les Britanniques en Amérique du Nord. Les soldats virginiens furent retirés des villages créoles pendant l'hiver de 1781-1782 et la Virginie prit la décision de ne pas renouveler l'administration du comté de l'Illinois à la fin de la période provisoire ${ }^{72}$. L'année suivante, Pierre Gibault, jésuite, à Kaskaskia résuma la situation au Pays des Illinois dans une lettre adressée à l'évêque de Québec, Jean-Olivier Briand: «Après avoir

68. Address of Colonel de La Balme, 17 septembre 1780, dans C. Walworth Alvord, dir., Kaskaskia Records..., p. 181-189.

69. Inhabitants of Cahokia to de La Balme, 21 septembre 1780, dans C. Walworth Alvord, dir., Cahokia Records, p. 535-553; Inhabitants of Kaskaskia to de La Balme, 29 septembre 1780, dans C. Walworth Alvord, dir., Kaskaskia Records..., p. 189-192.

70. Bradley J. Birzer, «French Imperial Remnants on the Middle Ground: The Strange Case of Auguste de La Balme and Charles Beaubien ", Journal of the Illinois State Historical Society, 93, 2 (été 2000), p. 144-147.

71. Petition to the Governor of Virginia from the Inhabitants of Kaskaskia, 4 mai 1781, dans C. Walworth Alvord, dir., Kaskaskia Records..., p. 233-240; John Todd Jr. to Thomas Jefferson, 2 juin 1780 ; John Rogers to Thomas Jefferson, 29 avril 1781, dans J. A. James, dir., The George Rogers Clark Papers, 17711781 , p. $422,545$.

72. C. W. Alvord, The Illinois Country, p. 352-354. 
été ruinés et épuisés par les Virginiens, laissés sans commandant, sans troupes et sans justice, ils [les Créoles] se gouvernent eux-mêmes par fantaisie et caprice, ou pour mieux dire par la loy du plus fort ${ }^{73}$.» Gibault décrivait une absence d'autorité impériale ${ }^{74}$. En réalité, la République américaine était aux prises avec ses propres problèmes politiques et économiques $^{75}$, dont la répression d'un soulèvement de nations autochtones confédérées de la vallée de l'Ohio.

\section{L'ABSENCE D’AUTORITÉ IMPÉRIALE ET LE RENOUVELLEMENT DE L'AUTORITÉ CRÉOLE FRANÇAISE}

Le traité de Paris de 1783 reconnaît la cession du Pays des Illinois, à l'est du Mississippi, aux États-Unis, mais c'est seulement en 1787 que les Américains entreprirent la mise en place d'un autre gouvernement. Dans l'intervalle, le Pays des Illinois resterait un territoire américain indéfini et sans administration ${ }^{76}$. Les Créoles étaient techniquement citoyens, ayant prêté serment d'allégeance à la république, mais l'absence d'un gouvernement représentatif local empêchait la reconnaissance des droits associés à la citoyenneté américaine. De plus, leurs anciens titres de propriété furent remis en question et, dans certains cas, le régime américain ne les confirmera pas avant le XIX ${ }^{\mathrm{e}}$ siècle. Réagissant à la situation, les Créoles se rabattirent sur les traditions du droit français et de la religion catholique pour assurer le bon fonctionnement de leurs communautés ${ }^{77}$.

Les églises fonctionnaient habituellement comme centres communautaires où les habitants assemblés décidaient du calendrier agricole, des activités sociales et des travaux de voirie ${ }^{78}$. En arrivant à Kaskaskia et à Cahokia en 1778, les Américains trouvèrent un seul curé, Pierre Gibault. L'expulsion des Jésuites de l'Amérique septentrionale en 1763 avait affaibli profondément l'Église catholique au Pays des Illinois. La région fut dépouillée de prêtres du jour au lendemain, à l'exception du Jésuite

73. Father Gibault to the Archbishop of Quebec, $1^{\text {er }}$ avril 1783, dans C. Walworth Alvord, dir., Kaskaskia Records..., p. 520.

74. Eric Hinderaker, Elusive Empires: Constructing Colonialism in the Ohio Valley, 1673-1800 (Cambridge, Cambridge University Press, 1997), p. 170.

75. Richard P. McCormick, "Ambiguous Authority: The Ordinances of the Confederation Congress", The American Journal of Legal History, 41, 4 (octobre 1997), p. 428; Reginald Horsman, "The Northwest Ordinance and the Shaping of an Expanding Republic», The Wisconsin Magazine of History, 73, 1 (automne 1989), p. 28.

76. La Virginie ne céda officiellement le pays des Illinois au gouvernement fédéral des États-Unis qu'en 1784, C. W. Alvord, The Illinois Country, p. 358.

77. M. K. Brown, History as They Lived It.., p. 110.

78. N. Belting, Kaskaskia..., p. 21, 68-71. 
Sébastien Louis Meurin et du Récollet Hippolyte Collet ${ }^{79}$. Meurin supplia l'évêché de Québec d'envoyer des renforts en 1767, ce à quoi l'évêque Briand répondit en envoyant un seul prêtre ${ }^{80}$. L’abbé Pierre Gibault, nouvellement arrivé au Pays des Illinois, entreprit la visite des villages et voyagea entre Kaskaskia, Cahokia, Vincennes, Ouiatanon, Peoria et Saint-Joseph. Pendant un temps, il s'occupa même des villages de Sainte-Geneviève et Saint-Louis sur l'autre rive du Mississippi, en territoire impérial espagnol ${ }^{81}$. Après le décès du père Meurin en 1777, il ne restait que Gibault pour desservir les Créoles et représenter l'Église catholique.

Disciple de l'évêque Briand, Gibault cherchait à assurer les liaisons entre les régimes impériaux et l'Église catholique, selon le modèle de la Province de Québec après la Conquête. Il encouragea donc la déférence créole d'abord au Régime britannique, et ensuite aux Américains. Mais sans une garantie de gouvernement civil, Gibault devait maintenir une position délicate, car les Créoles désiraient la reconnaissance de leurs coutumes et la garantie de leurs droits de citoyenneté. Comme si la situation n'était pas déjà suffisamment compliquée, la question de la juridiction ecclésiastique au Pays des Illinois causée par le changement de régime ne fut pas réglée avant 1791, au moment où le territoire fut transféré au diocèse de Baltimore ${ }^{82}$. Cela étant dit, les Créoles continuaient à pratiquer la religion catholique, souvent sans curé, à célébrer les festivités selon le calendrier chrétien et à utiliser les églises comme centres communautaires, tout en attendant le rétablissement d'une autorité ecclésiastique.

Depuis le début du siècle, tout comme dans l'Amérique française en général, la Coutume de Paris s'appliquait au Pays des Illinois et gouvernait la vie socio-économique créole ${ }^{83}$. Une cour civile exista brièvement entre 1768 et 1770 à Kaskaskia, à laquelle la population élit des magistrats

79. Marcel Trudel, «Les Récollets sous le régime militaire», Revue d'histoire de l'Amérique française, 10,2 (1956), p. 9, 28.

80. Daniel Hechenberger, «The Jesuits: History and Impact: From Their Origins Prior to the Baroque Crisis to Their Role in the Illinois Country ", Journal of the Illinois State Historical Society, 100, 2 (été 2007), p. 101.

81. Joseph P. Donnelly, "Pierre Gibault and the Critical Period of the Illinois Country", dans John Francis McDermott, dir., The French in the Mississippi Valley (Urbana, University of Illinois Press, 1965), p. $81-91$.

82. Gilbert J. Garraghan, "The Ecclesiastical Rule of Old Quebec in Mid-America», The Catholic Historical Review, 19, 1 (avril 1933), p. 30. La Louisiane fut placée sous l'autorité du diocèse of Santiago de Cuba en 1777. Le diocèse de Baltimore fut établi en 1784.

83. John A. Dickinson, «New France: Law, Courts, and the Coutume de Paris, 1608-1760», Manitoba Law Journal, 23 (1995), p. 38-40; Carl J. Ekberg et Sharon K. Person, St. Louis Rising: The French Regime of Louis St. Ange de Bellerive (Champaign, University of Illinois Press, 2015), p. 127-146; Arnaud Balvay, L'épée et la plume: Amérindiens et soldats des troupes de la marine en Louisiane et au Pays d'en haut, 1683-1763 (Québec, Les Presses Université Laval, 2006), p. 274-278; M. K. Brown, History as They Lived It..., p. 42-45; Éric 
créoles qui manifestèrent leur opposition au Régime britannique au Pays des Illinois. Le lieutenant Todd institua trois districts judiciaires dans le comté d'Illinois en 1779, reconstituant celui de Kaskaskia et créant de nouveaux districts à Cahokia et à Vincennes ${ }^{84}$.

Comme ce fut le cas dans la Province de Québec, aux Pays d'en Haut et en Louisiane, le changement de régime au Pays des Illinois entraîna une intensification du pluralisme juridique ${ }^{85}$. Quelques notaires furent nommés greffiers, mais ceux-ci continuèrent en fait à accomplir plusieurs des tâches qui leur incombaient sous le Régime français. Par ailleurs, l'orientation des magistrats et des jurés du nouveau régime visait à faire respecter la coutume ${ }^{86}$. Ainsi, les Créoles au Pays des Illinois utilisèrent le système judiciaire pour favoriser le maintien des lois françaises et pour protéger l'autonomie de leurs villages par rapport à l'expansion impériale américaine. Ensemble, la religion et le droit fonctionnaient comme mécanismes de contrôle social qui renforçaient, voire imposaient, les principes et coutumes de la société créole ${ }^{87}$.

La mesure par laquelle les institutions religieuses et juridiques contribuèrent à l'expression de l'autonomie créole dépendait cependant du contexte particulier de chaque village. Pendant la majeure partie de la période du comté d'Illinois (1779-1781), la population créole à Kaskaskia présenta un front largement uni face aux Virginiens. Par la suite, plusieurs factions politiques émergèrent. Tandis que le nouveau lieutenant du comté, Richard Winston, se querellait avec les magistrats et leur président, Jacques La Source, au sujet de l'autorité de la cour civile, les rares militaires virginiens qui demeuraient au village contestèrent le pouvoir de Winston ${ }^{88}$. Le mar-

Wenzel, "Justice et culture militaires dans le Pays des Illinois au XVIII ${ }^{\mathrm{e}}$ siècle à travers une affaire de désertion (1752)", Revue d'histoire de l'Amérique française, 68, 1-2 (2014), p. 86-87.

84. M. K. Brown, History as They Lived It..., p. 72-73.

85. Hans W. Baade, "Marriage Contracts in and French and Spanish Louisiana: A Study in "Notarial" Jurisprudence", Tulane Law Review, 53, 1 (1979), p. 1-92; Evelyn Kolish, Nationalismes et conflits de droits : le débat du droit privé au Québec, 1760-1840 (LaSalle, Hurtubise HMH, 1994), chap. 1-3; Stuart Banner, "Written Law and Unwritten Norms in Colonial St. Louis», Law and History Review, 14, 1 (1996), p. 33-80; Michel Morin, Arnaud Decroix et David Gilles, Les Tribunaux et l'arbitrage en Nouvelle-France et au Québec de 1740 à 1784 (Montréal, Éditions Thémis, 2011), p. 32-33 ; C. J. Ekberg et S. K. Person, St. Louis Rising..., p. 127-146; Donald Fyson, "The Conquered and the Conqueror: The Mutual Adaptation of the Canadiens and the British in Quebec, 1759-1775 ", dans Phillip Buckner et John G. Reid, dir., Revisiting 1759: The Conquest of Canada in Historical Perspective (Toronto, University of Toronto Press, 2012), p. 190217; B. Saler, The Settlers' Empire..., p. 21, 114; L. E. Murphy, Great Lakes Creoles..., chap. 3.

86. R. Englebert, "The Legacy of New France...", p. 41.

87. Jésus F. de la Teja et Ross Frank, dir., Choice, Persuasion, and Coersion : Social Control on Spain's North American Frontiers (Albuquerque, University of New Mexico Press, 2005), p. xiii.

88. Placard Concerning Office of Notary by Richard Winston, 30 août 1781; Jacques la Source to the Magistrates of the Court of Kaskaskia, ${ }^{\text {er }}$ septembre 1781, dans C. Walworth Alvord, dir., Kaskaskia Records..., p. 262, 266. 
chand John Dodge profita de l'incertitude politique pour établir un régime quasi despotique. Avec l'aide de la faction des militaires, incluant son frère le lieutenant Israel Dodge, il arrêta Winston et l'accusa de trahison le 29 avril $1782^{89}$.

En se présentant comme magistrat en chef et en se donnant lui-même le faux titre de Captain Commandant, Dodge provoqua une crise judiciaire encore plus grave ${ }^{90}$. L'impopularité de Winston poussa certains Créoles, notamment le notaire Joseph Labuxière fils, à soutenir les actions de Dodge $^{91}$. Par ailleurs, l'huissier Blaise Barutel contesta la collaboration Labuxière-Dodge en refusant l'assignation des témoins dans le procès intenté contre Winston le 2 mai $1782^{92}$. Les habitants créoles condamnèrent Dodge et les magistrats dans une pétition présentée à la cour civile le 25 mai $1782^{93}$. Bien que le factionnalisme produisit une grande incertitude judiciaire, Winston fut libéré à la suite de deux procès. Dans un ultime effort pour rétablir l'ordre à Kaskaskia à la fin de novembre 1782, Winston dissout la cour civile ${ }^{94}$. En fin de compte, l'opposition à Winston fut trop importante; il démissionna deux mois plus tard et nomma Jacques Timothée Boucher Sieur de Montbrun lieutenant du comté par intérim ${ }^{95}$. Dans un véritable coup d'État, en 1784, John Dodge prit l'ancien fort de Kaskaskia en plaçant sur l'escarpement deux canons qui pointaient vers le village ${ }^{96}$. Sans que Dodge ait à recourir à la force, Montbrun devint un homme de paille, lieutenant en titre seulement du comté - dont l'existence n'avait pas été renouvelée - de l'Illinois. Le régime de John Dodge se poursuivit pendant trois années, jusqu'à ce que les Créoles le déposent.

Au cours de cette période d'instabilité, Kaskaskia fut divisé en trois factions plus ou moins distinctes: les partisans des anciens magistrats créoles; ceux qui continuaient d’appuyer Winston; ceux qui soutenaient Dodge. Les

89. Richard Winston's Protest Against his Arrest, 29 avril 1782, dans C. Walworth Alvord, dir., Kaskaskia Records..., p. 274.

90. The Arrest of Richard Winston, 29 avril 1782, dans C. Walworth Alvord, dir., Kaskaskia Records..., p. $272-273$.

91. Examination of Witnesses by Labuxiere, 2 mai 1782; John Dodge to Joseph Labuxiere, 4 mai 1782, C. Walworth Alvord, dir., Kaskaskia Records..., p. 278, 282-283.

92. Illinois State Archives Springfield Illinois (ISA), Perrin Collection, p. 52 \#196, Statement of Michel Perrault, le 2 mai 1782.

93. Inhabitants of Kaskaskia to the Magistrates, 25 mai 1782, dans C. Walworth Alvord, dir., Kaskaskia Records..., p. 285.

94. C. W. Alvord, The Illinois Country..., p. 361.

95. Commission of County-Lieutenant by Richard Winston to Timothé de Monbreun, 18 janvier 1783 ; Richard Winston Announces Appointment of De Monbreun, 21 janvier 1783, dans C. Walworth Alvord, dir., Kaskaskia Records..., p. 320, 328-329. Dans les sources américaines, Boucher de Montbrun, né à Boucherville, est désigné sous le nom de Timothé Boucher Sieur de Monbreun.

96. C. W. Alvord, The Illinois Country..., p. 362. 
événements dramatiques de 1782 avaient segmenté l'opinion créole à Kaskaskia en ce qui concerne les bonnes tactiques pour préserver leurs droits et influencer la gouvernance au Pays des Illinois. Des délégués de Kaskaskia, Cahokia et Vincennes rencontrèrent les commissaires de la Virginie à Fort Nelson, à la fin de mars 1783, et leur demandèrent des réparations pour compenser les pertes subies pendant la révolution ${ }^{97}$. Trois individus (Richard Winston, François Charbonneau et John Williams) représentaient Kaskaskia. Chacun était muni de pétition, reflétant des factions politiques clairement distinctes les unes des autres. Les deux premières pétitions se penchèrent sur la dissolution de la cour à Kaskaskia et la dernière rappelait les prétendus abus de Winston ${ }^{98}$.

Le 22 juin 1784, quatre anciens magistrats - Antoine Bauvais, Antoine Morin, Nicholas Caillot dit Lachance et Pierre Langlois - appuyèrent ouvertement la faction Dodge, en signant sa pétition destinée au Congrès continental des États-Unis ${ }^{99}$. Quoiqu’on ne sache pas clairement pourquoi les Créoles influents se joignirent à Dodge, on sait qu'ils avaient bénéficié de généreuses concessions de terres qu’il avait approuvées ${ }^{100}$. Ces transfuges représentaient pourtant un faible appui. La majorité de la population créole s'opposait à Dodge, et aux Américains de manière plus générale, même si elle était toujours divisée en factions. Dans sa lettre datée du 7 novembre 1785, John Edgar, marchand américain et membre de la faction Dodge, décrivit une forte opposition créole en disant que «nos voisins français... disent ouvertement qu'ils vont s'opposer à tous les Américains qui arrivent dans ce pays ${ }^{101} \ldots$ ».

L'inimité manifestée envers Dodge correspondait au rétablissement de l'autorité ecclésiastique en 1785-1786. John Carroll, préfet apostolique des États-Unis, nomma Paul de Saint-Pierre et Pierre Huet de la Valinière, un

97. Proclamation of Virginia Commissioners, 4 décembre 1782, dans C. Walworth Alvord, dir., Kaskaskia Records..., p. 317-319.

98. Commission as Agents to Richard Winston and François Carbonneaux, 3 décembre 1782; Memorial of the Inhabitants of Illinois to the Commissioners of the State of Virginia, ${ }^{\text {er }}$ mars 1783 ; Memorial of the Principal Inhabitants of Illinois to the Commissioners of the State of Virginia, mars 1783 ; Richard Winston and Others to George R. Clark, 30 mars 1786, dans C. Walworth Alvord, dir., Kaskaskia Records..., p. 315-317, 335, 340, 346.

99. Memorial to Congress by the Faction of John Dodge, 22 juin 1784, dans C. Walworth Alvord, dir., Kaskaskia Records..., p. 368. Il est désigné sous le nom de Lachanse dans les documents.

100. ISA, Raymond H. Hammes Collection, Reel 2, Kaskaskia French and English Deed Records, Surveys 1810-1816, Auditor of Public Accounts, p. 54-56.

101. John Edgar to George Rogers Clark, 7 novembre 1785, dans C. Walworth Alvord, dir., Kaskaskia Records..., p. 376. 
carmélite allemand et un sulpicien français, au Pays des Illinois ${ }^{102}$. À son arrivée en 1785, Saint-Pierre s'impliqua dans la politique villageoise de Kaskaskia. John Edgar et Louis Tournier, membres de la faction Dodge, l'accusèrent de diffamation et s'engagèrent à le poursuivre en justice en faisant appel à Nicholas Lachance, ancien magistrat de la cour dissoute. Alors que la cour était abolie à Kaskaskia, il semble que la faction Dodge cherchait à employer les magistrats élus antérieurement comme des juges ad hoc. Saint-Pierre refusa de témoigner devant Lachance en lui répondant «... vous nete pas qualifié pour Juger Les personnes Eclasiastiques, et avec Les même Je fais mils protestations contre vos ordres - tres mal Employées $^{103}$ ». Lachance reconnut que l'autorité ecclésiastique était en dehors de sa prétendue juridiction.

L'année suivante, Pierre Huet de la Valinière arriva à Kaskaskia et SaintPierre déménagea à Cahokia pour servir la paroisse de Sainte-Famille. L'historien Clarence Alvord a conclu que l'arrivée de la Valinière marque un tournant à partir duquel les Créoles reprennent des formes de résistance plus concertées ${ }^{104}$. Cependant, tout indique que les actions de l'abbé Paul de Saint-Pierre contribuèrent elles aussi à cette tendance. En contestant la légitimité de la faction Dodge, il donna un nouveau souffle à l'opposition créole à Kaskaskia. Le 2 juin 1786, une faction représentant les Créoles antiDodge soumit une pétition au Congrès continental des États-Unis, demandant encore une fois un gouvernement civil pour défendre les habitants créoles et protéger leurs droits de propriété ${ }^{105}$. En même temps, la discorde créole, qui avait marqué le début du régime Dodge, se dissipa. Avec la manifestation d'une forte opposition créole, John Dodge se rendit compte de sa position précaire et s'enfuit de la région au printemps $1787^{106}$.

Cahokia ne connut pas les mêmes épreuves que Kaskaskia. La présence américaine y était moins prononcée, ce qui limita les perturbations politiques. Le village bénéficiait aussi d’une stabilité économique grâce aux liens socio-économiques avec le village de Saint-Louis, juste de l'autre côté du

102. John Rothensteiner, "Paul de Saint Pierre: The First German-American Priest of the West», The Catholic Historical Review, 5, $2 / 3$ (1919), p. 195-222; Lucien Lemieux, "Huet de la Valinière, Pierre», dans Dictionnaire biographique du Canada, vol. 5 (Toronto/Québec, University of Toronto/Université Laval, 2003-), < http ://biographi.ca/fr/bio/huet_de_la_valiniere_pierre_5F.html > .

103. John Edgar and Louis Tournier versus Father St. Pierre, 27 juillet 1785, dans C. Walworth Alvord, dir., Kaskaskia Records..., p. 526.

104. C. W. Alvord, The Illinois Country..., p. 365.

105. Memorial of the French Faction to Congress, 2 juin 1786, dans C. Walworth Alvord, dir., Kaskaskia Records..., p. 381.

106. C. J. Ekberg, French Roots..., p. 226. 
Mississippi ${ }^{107}$. Pendant les années 1780 , Saint-Louis supplanta Kaskaskia comme principal centre de la traite des fourrures et s'établit comme métropole créole et moteur économique de la zone limitrophe du Pays des Illinois, malgré son emplacement en territoire espagnol. Enfin, et peut-être plus importante encore, était la continuité du système juridique français ${ }^{108}$. De 1782 à 1788, les magistrats de cour de Cahokia furent élus lors d'élections annuelles. En revanche, après trois élections tenues en 1782, la cour de Kaskaskia fut abolie ${ }^{109}$. La cour de Cahokia jouera un rôle fondamental dans la préservation des lois françaises et de la lutte pour l'autonomie créole face aux Américains.

Entre 1780 et 1787, pendant que les membres du Congrès américain discutaient entre eux de la façon d'intégrer de nouveaux territoires dans l'union des États-Unis ${ }^{110}$, certains Anglo-Américains protestants s'enracinèrent dans les villages de Bellefontaine et Grand Ruisseau dans les districts de Kaskaskia et de Cahokia. En 1782, les familles américaines de Bellefontaine adressèrent une pétition à la cour de Kaskaskia pour la création de leur propre cour villageoise, requête qui fut acceptée par les magistrats ${ }^{111}$. Les gens de Cahokia interprétèrent la mise en place d'une cour à Bellefontaine comme une américanisation du système menant à l'assimilation des Créoles. Quand les familles américaines de Grand Ruisseau cherchèrent à imiter leurs voisins de Bellefontaine quatre ans plus tard, les magistrats créoles de Cahokia refusèrent leur requête ${ }^{112}$. Ils demeurèrent indéfectibles dans leur soutien de l'autorité judiciaire de la cour de Cahokia et de ses lois françaises comme mécanisme pour défendre les mœurs créoles dans le village de Grand Ruisseau.

Comme il a été déjà mentionné, l’abbé Paul de Saint-Pierre arriva à Cahokia en 1786 pour rétablir l'autorité de l'Église catholique. La paroisse

107. C. J. Ekberg, French Roots..., p. 55 ; M. K. Brown, History as They Lived It..., p. 192.

108. Charles E. Peterson, «Notes on Old Cahokia: Part Three: American Domination (1778-1790)», Journal of the Illinois State Historical Society, 42, 3 (septembre 1949), p. 316.

109. Élections tenues les 20 juin 1782, 26 mai 1783, 20 mai 1784, 6 juin 1786, $1^{\text {er }}$ juin 1787 et 18 août 1788, dans C. Walworth Alvord, dir., Cahokia Records..., p. 130, 146, 166, 240, 296, 338; Élections du 10 février 1782 et du 15 septembre 1782, dans C. Walworth Alvord, dir., Kaskaskia Records..., p. 271, 301-302.

110. Robert S. Hill, «Federalism...», p. 41-52. Aujourd'hui Bellefontaine fait partie de la ville de Waterloo, Illinois. L'emplacement de Grand Ruisseau était à un mille et demi $(2,4 \mathrm{~km})$ à l'ouest de la ville actuelle de Columbia, Illinois.

111. Petition of the American Settlers of Bellefontaine to the Court of the District of Kaskaskia for Some Form of Civil Government. Le 9 juillet 1782; Election at Bellefontaine. Le 5 août 1782, dans C. Walworth Alvord, dir., Kaskaskia Records..., p. 294-296.

112. Inhabitants of Cahokia to Congress. Le 10 novembre 1784 ; Court Session. Le 2 janvier 1786 et le 2 novembre 1787, dans C. Walworth Alvord, dir., Cahokia Records..., p. 217-219, 307, 569. 
de la Sainte-Famille comprenait l'entièreté du district de Cahokia. Bien que Grand Ruisseau fut principalement constitué de familles américaines, les Créoles s'attendaient à ce que toutes les familles du district pourvoient aux besoins du curé et de l'Église, en dépit des différences confessionnelles. Ensemble, la cour et l'Église donnèrent leur appui aux coutumes créoles en exerçant le contrôle social ${ }^{113}$. Entre 1786 et 1789 , la cour à Cahokia en vint à exiger que tous, catholiques et non-catholiques, payent la dîme $\mathrm{e}^{114}$. Au premier regard, cela semble être en contradiction avec l'histoire de la région, où l'autonomie créole avait notamment été reflétée par une tradition de non-paiement de la dîme ${ }^{115}$. L'abbé Meurin avait écrit à l'évêque de Québec en 1768 au sujet des difficultés de récolter la dîme au Pays des Illinois, le suppliant de trouver une manière d'obliger les Créoles à la payer ${ }^{116}$. En 1789, la cour à Cahokia imposait non seulement la dîme, mais aussi des contraventions pour les récalcitrants, incluant même la saisie de propriétét ${ }^{117}$.

En surface, tout cela représente une étonnante volte-face, mais en fait la décision des magistrats témoigne d'une logique bien cohérente. Paiement identique à celui que les habitants devaient faire à l'Église catho-

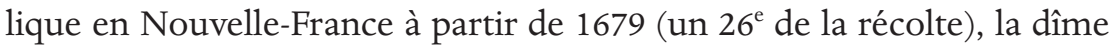
symbolisait un lien socioculturel avec le patrimoine français en Amérique du Nord ${ }^{118}$. Les magistrats de Cahokia utilisèrent le pouvoir de la cour pour intégrer les Américains à la culture créole majoritaire et affirmer la prédominance de l’Église catholique dans un district judiciaire américain. Ainsi, dans les faits, la cour de Cahokia défendait l'autorité ecclésiastique afin de confirmer l'autonomie politique créole.

Comme on pouvait s'y attendre, les Américains au Pays des Illinois ripostèrent à ce qu'ils percevaient comme une attaque créole. Pendant l'été 1786, deux Virginiens, James Piggot et Benjamin Rogers, furent inculpés pour un complot qui visait à ravir le pouvoir judiciaire créole à

113. Court Session. Le $1^{\text {er }}$ décembre 1786 , le 2 janvier 1789 et le 6 avril 1789 , dans Clarence Walworth Alvord, dir., Cahokia Records..., p. 257, 351-353, 369.

114. Court Session. Le 6 avril 1789 et le 2 mars 1789, dans Clarence Walworth Alvord, dir., Cahokia Records..., p. 365, 369.

115. R. M. Morrissey, Empire by Collaboration..., p. 162.

116. Letter of Father Sébastien Louis Meurin to Monseigneur Briand, Bishop of Quebec. Le 11 juin 1768, dans Reuben Gold Thwaites, dir., The Jesuit Relations and Allied Documents: Travels and Explorations of the Jesuit Missionaries in New France 1610-1791, vol. LXXI (Cleveland, The Burrows Company, 1901), p. 39.

117. Court Session. Le 6 avril 1789, dans Clarence Walworth Alvord, dir., Cahokia Records..., p. 369.

118. Allan Greer, Peasant, Lord, and Merchant: Rural Society in Three Quebec Parishes, 1740-1840 (Toronto, University of Toronto Press, 1985), p. 114; T. Villerbu, «Pouvoir, religion et société... », p. 212-213. 
Grand Ruisseau ${ }^{119}$. Ils furent mis aux fers pendant vingt-quatre heures, puis on leur interdit d'aller au village voisin de Bellefontaine ${ }^{120}$. Le bannissement de la région constituait finalement une punition relativement légère si on la compare à l'emprisonnement. La cour prit peut-être en compte l'accroissement de l'immigration américaine et l'opinion de cette population.

L'alliance entre la cour civile et l'Église catholique à Cahokia était en pleine contradiction avec la séparation de la politique et de la religion comme principe fondamental de la Révolution américaine et de la constitution en cours de préparation ${ }^{121}$. Les Créoles avaient épousé les principes de la Révolution à plusieurs reprises dans leurs pétitions, mais avaient changé de tactique en l'absence d'autorité à la suite de la dissolution du comté de l'Illinois en 1782. Le rétablissement de l'autorité ecclésiastique, combiné au pouvoir judiciaire à Cahokia, donna l'occasion de protéger la société créole, mais ne l'empêcha pas de revendiquer les droits de citoyenneté américaine en utilisant la rhétorique républicaine.

\section{CONCLUSION}

À première vue, les efforts des Créoles apparaissent peut-être comme une série d'échecs sur le plan de l'expression d'autonomie locale et culturelle. Or, ils réussirent en fait à jeter les bases de leur résistance contre l’hégémonie américaine. Les Créoles manipulèrent la notion de liberté américaine afin de poursuivre leurs propres objectifs. De plus, les méthodes de résistance - les pétitions, les élections de magistrats et les porte-paroles - perdurèrent au-delà de la dissolution du régime virginien en 1782.

La fin du comté de l'Illinois créa une nouvelle dynamique dans laquelle les anciens piliers de la société jouèrent des rôles déterminants, notamment en ce qui concerne la défense de l'autonomie créole. La dissolution de la cour civile à Kaskaskia au début du régime Dodge exacerba les factions politiques, tandis que la stabilité de la cour à Cahokia assura une voie créole concertée pour résister aux Américains. Le rétablissement de l'autorité ecclésiastique contribua au renouvellement de l'opposition contre Dodge à Kaskaskia, donnant des moyens aux Créoles d'exercer un contrôle social sur les familles américaines dans le district de Cahokia.

119. ISA, Perrin Collection, p. 45 \#13, 50 \#119, Petition, le 14 juillet 1787, Court Record, le 17 septembre 1787.

120. ISA, Perrin Collection, p. 45 \#13, Court Record, le 17 septembre 1787.

121. Daniel L. Dreisbach, «The Constitution’s Forgotten Religion Clause: Reflections on Article VI Religious Test Ban ", Journal of Church and State, 38, 2 (printemps 1996), p. 262. 
Pourtant, ce rétablissement dépendait du curé en question, car l'abbé Saint-Pierre contribua nettement plus à la résistance créole que les pères Gibault et Valinière. Dans l'ensemble, cette comparaison des événements dans les districts de Kaskaskia et Cahokia permet de mieux comprendre de quelle façon les traditions des institutions judiciaires et religieuses furent essentielles aux revendications créoles au cours de la période révolutionnaire américaine.

En 1787, le colonel Josiah Harmar arriva au Pays des Illinois pour rétablir le contrôle militaire américain et y décrivit un pays en désordre ${ }^{122}$. Cependant, sa représentation du pays ne prenait pas en compte le fait que les Créoles exerçaient le contrôle social selon leurs lois et coutumes. En dépit des factions politiques à Kaskaskia et des individus qui poursuivirent leurs intérêts personnels, la majorité de la population créole sut résister à l'hégémonie américaine au cours de la Révolution. En fin de compte, Arthur St. Clair, le gouverneur du Territoire du Nord-Ouest en 1790, dut faire face au défi d'intégrer une population créole largement autonome dans le projet d'expansion impériale américain vers l'Ouest, afin d'intégrer celle-ci au cœur d’une nouvelle société américaine. 